\title{
Nitrosonium Cation as a Cytotoxic Component of Dinitrosyl Iron Complexes with Thiol-containing Ligands (based on the Experimental Work on MCF7 Human Breast Cancer Cell Culture)
}

\author{
Anatoly F. Vanin $\mathbb{D}^{1,2} \cdot$ Viktor A. Tronov ${ }^{1} \cdot$ Rostislav R. Borodulin ${ }^{1}$ \\ Accepted: 7 December 2020 / Published online: 25 January 2021 \\ (c) The Author(s), under exclusive licence to Springer Science+Business Media, LLC part of Springer Nature 2021
}

\begin{abstract}
Here we demonstrate that binuclear dinitrosyl iron complexes with thiol-containing ligands (glutathione and mercaptosuccinate, B-DNIC-GSH and B-DNIC-MS, respectively) exert cytotoxic effects on MCF7 human breast cancer cells. We showed that they are mediated by nitrosonium cations released from these complexes $\left(\mathrm{NO}^{+}\right)$. This finding is supported by the cytotoxic effect of both B-DNICs on MCF7 cells evidenced to retain or was even promoted in the presence of N-Methyl-D-glucamine dithiocarbamate (MGD). MGD recruits an iron nitrosyl group [ $\mathrm{Fe}(\mathrm{NO})]$ from the iron-dinitrosyl fragment $\left[\mathrm{Fe}(\mathrm{NO})_{2}\right]$ of B-DNIC-MS forming stable mononitrosyl complexes of iron with MGD and releasing $\mathrm{NO}^{+}$cations from a $\left[\mathrm{Fe}(\mathrm{NO})_{2}\right]$ fragment.
\end{abstract}

Keywords Dinitrosyl iron complexes $\cdot$ Nitric oxide $\cdot$ Nitrosonium cations $\cdot$ Apoptosis

\section{Introduction}

Currently, there is amounting evidence indicating that dinitrosyl iron complexes (DNIC) with thiol-containing ligands produced in animal cells and tissues in the presence of nitric oxide (NO) act as a "working form" of NO [1-3]. Embedding NO into these complexes ensures its stabilization and further transfer to biological targets. Moreover, it is accompanied by the transformation of about a half of $\mathrm{NO}$ molecules into nitrosonium cations $\left(\mathrm{NO}^{+}\right)$. As a result, DNIC with thiol-containing ligands can serve as $\mathrm{NO}$ donors as well as $\mathrm{NO}^{+}$donors. Nitrosonium cations are crucial for S-nitrosylation of biologically active thiol-containing proteins and small molecules, thus, performing an essential biological activity of the endogenous NO network [3-22]. DNIC with thiol-containing ligands have been shown to induce this process for

Anatoly F. Vanin

vanin.dnic@gmail.com

1 Semenov Federal Research Centre of Chemical Physics, Russian Academy of Sciences, Moscow, Russia

2 Institute of Regenerative Medicine, Sechenov Medical University, Moscow, Russia isolated proteins $[5,7-10,17]$ as well as endogenous proteins [9-11, 14, 16, 18]. Incorporating neutral NO molecules and nitrosonium cations into DNIC is determined by the mechanism of the complex formation. Its mechanism is mediated by the disproportionation reaction of NO molecules initiated by their binding to ferrous iron (two NO molecules per one $\mathrm{Fe}^{2+}$ ion, Scheme 1), as shown by our group:

One of the resonance structures of paramagnetic mononuclear DNIC with thiol-containing ligands formed according to Scheme 1 can be represented as $\left[\left(\mathrm{RS}^{-}\right)_{2} \mathrm{Fe}^{+}\left(\mathrm{NO}^{+}\right)_{2}\right]^{+}$. The reaction corresponding to the suggested mechanism of M-DNIC formation described in detail in $[1-3,6,13,19-22]$. is as follows (reaction 1):

$\mathbf{F e}^{2+}+2 \mathbf{R S H}+3 \mathrm{NO} \rightarrow\left[\left(\mathbf{R S}^{-}\right)_{2} \mathrm{Fe}^{+}\left(\mathrm{NO}^{+}\right)_{\mathbf{2}}\right]^{+}+1 / 2\left(\mathbf{H}_{\mathbf{2}} \mathbf{O}+\mathbf{N}_{\mathbf{2}} \mathbf{O}\right)$

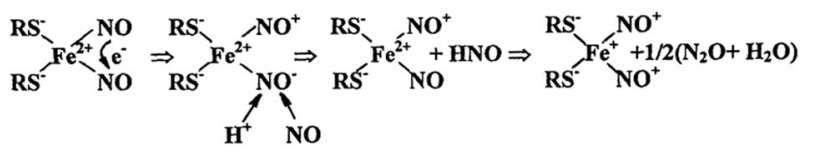

Scheme 1 A possible way of mononuclear DNIC with thiol-containing ligands formation in the reaction of ferrous iron, thiols, and gaseous NO 
The reverse process is a degradation of the complexes that can be caused by various agents: iron chelators, compounds that block or oxidize thiols, NO oxidizing agents. Hence, the reverse process ought to trigger the release of $\mathrm{Fe}^{2+}$, neutral $\mathrm{NO}$ molecules (as a result of the electron transfer from $\mathrm{Fe}^{+}$on one of the nitrosyl $\mathrm{NO}^{+}$ligands), nitrosonium cations, and thiol-containing ligands from DNIC according to the properties of an agent [1-3].

It should be noted that the ability of DNIC to serve as a donor of $\mathrm{Fe}^{2+}$, thiols, $\mathrm{NO}$ molecules, and nitrosonium cations (given the degradation mechanisms) is typical of a mononuclear form of DNIC (M-DNIC, mentioned above) as well as a binuclear form of these complexes (B-DNIC). $\mathrm{B}-\mathrm{DNIC}$ is characterized by the resonance structure similar to that of M-DNIC: $\left[\left(\mathrm{RS}^{-}\right)_{2} \mathrm{Fe}^{+}{ }_{2}\left(\mathrm{NO}^{+}\right)_{4}\right]^{4+}[1-3,18-21]$. BDNIC is formed of M-DNIC upon a decline in the content of thiol-containing ligands following the mechanism of reversible interconversion of M-DNIC and B-DNIC (Scheme 2):

Currently, DNIC with thiol-containing ligands have been shown to trigger the formation of S-nitrosothiols in cell culture which act as donors of nitrosonium cations $[9,10,14-16,18]$. Particularly, this process was shown to be independent of the presence of oxygen in the intracellular environment $[16,18]$. This fact contradicts the statement made in [23] that the S-nitrosylating activity of DNIC is mediated by the oxidation of $\mathrm{NO}$ released from these complexes into nitrogen dioxide $\left(\mathrm{NO}_{2}\right)$ with the subsequent formation of the $\mathrm{NO}$ adduct $\mathrm{NO}_{2}-\mathrm{NO}$ (nitrotrioxide) capable of thiol S-nitrosylation.

The fundamental premise of this study was based mostly on the work of the group of T. Münzel [14]. They were the first to show that the cytotoxic activity of DNIC with thiosulfate on the culture of transformed Jurkat cells (human leukemic T-cells) is mediated by nitrosonium cations released from DNIC rather than NO molecules (14). This

$$
\begin{aligned}
\text { M-DNIC } & \stackrel{-\mathrm{RS}^{-}}{\rightleftarrows} \underset{+\mathrm{RS}^{-}}{\rightleftarrows}-\mathrm{B}-\mathrm{DNIC}
\end{aligned}
$$

Scheme 2 Reversible interconversion of M-DNIC and B-DNIC with thiol-containing ligands [1-3, 27] conclusion emerged from the observation that DNIC cytotoxic activity was not reduced and was even elevated after the complete degradation of the complexes by a dithiocarbamate derivative (N-Methyl-D-glucamine dithiocarbamate, MGD). MGD can intercept the iron mononitrosyl group $\left(\mathrm{Fe}^{2+}-\mathrm{NO}\right)$ from iron dinitrosyl fragment $\left(\mathrm{Fe}(\mathrm{NO})_{2}\right)$ of DNIC forming the mononitrosyl iron complexes with MGD (MNIC-MGD) that can be detected by EPR, according to Scheme 3. This led to the transfer of NO molecules to the MNIC-MGD complex which is more stable than DNIC and were not able to affect Jurkat cells. Thus, the cytotoxic effects could be induced only by the nitrosonium cations released from DNIC and capable of Snitrosating various thiol groups (Scheme 3 ).

The elevated cytotoxicity of DNIC with thiosulfate in the presence of MGD could be caused by the cytotoxic activity of MGD. However, the proposed estimation of the individual cytotoxic effects of $0.1 \mathrm{mM}$ DNIC or $0.2 \mathrm{mM}$ MGD showed that the sum of their individual cytotoxic effects was significantly lower than the effect of a combined treatment of Jurkat cells with the same concentrations of DNIC and MGD [14]. Therefore, the elevated effect could be promoted by the activity of MGD toward DNIC degradation. MGD increased the levels of nitrosonium cations in the cell environment. They S-nitrosylated thiol-containing proteins inducing apoptosis of Jurkat cells.

In this work, we studied the cytotoxic activity of B-DNIC with glutathione or mercaptosuccinate (B-DNIC-GSH or BDNIC-MS, respectively) on the MCF7 human breast cancer cells in either the absence or presence of MGD.

Our results confirmed the main results of the work [14] that the cytotoxic activity of DNIC with thiol-containing ligands mainly stems from nitrosonium cations rather than NO molecules released from these complexes.

\section{Materials and Methods}

\section{Materials}

We used ferrous sulfate (Fluka, Buchs, Switzerland), reduced glutathione (GSH), sodium mercaptosuccinate
Scheme 3 The mechanism of the conversion of B- and M-DNIC with thiol-containing ligands into MNIC with dithiocarbamate ligands. Released $\mathrm{NO}^{+}$cations can S-nitrosylate low-molecular and protein-bound thiol groups or dithiocarbamate detivatives

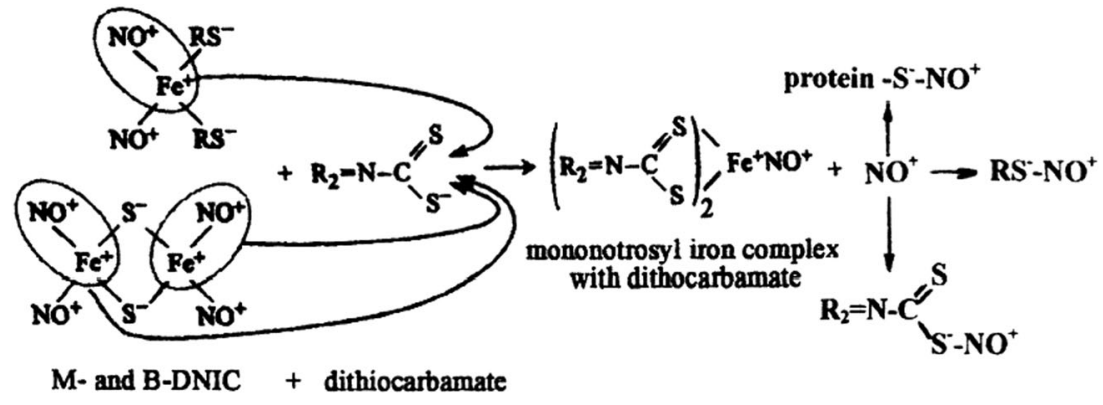


(MS), and sodium nitrite (all purchased from Sigma, St. Louis, USA). MGD was synthesized following the method described in [24].

\section{Synthesis of B-DNIC with Glutathione and Mercaptosuccinate}

To synthesize B-DNIC with thiol-containing ligands glutathione (B-DNIC-GSH) and mercaptosuccinate (B-DNICMS), we used the ability of S-nitrosothiols (RS-NO), GS-NO or MS-NO, respectively, to produce M-DNIC with thiol-containing ligands during the reaction of two RS-NO molecules with $\mathrm{Fe}^{2+}$ ions and two thiol molecules, according to Scheme 4:

Following this scheme, $\mathrm{Fe}^{2+}$ ion binds to two RS-NO molecules forming the resonance structure of $\mathrm{NO}^{+}-\mathrm{RS}^{-}$. The resulting disproportionation reaction (an one-electron transfer) can lead to the immediate generation of DNIC due to the breakdown of S-nitrosothiol ligands. The subsequent formation of B-DNIC was caused by condensation of two M-DNIC, according to Scheme 2. As thiols could be incorporated into B-DNIC in an ionized state $\left(\mathrm{RS}^{-}\right)$, most of M-DNIC underwent a transformation into B-DNIC due to weak ionization of these groups in GSH and MS at neutral (physiological) $\mathrm{pH}$.

Following the protocol of B-DNIC-GSH synthesis designed by our group [25] and represented by Scheme 3, these complexes were synthesized as described below. Glutathione, ferrous sulfate, and nitrite were added consequently to $10 \mathrm{ml}$ of $15 \mathrm{mM}$ HEPES, pH 7.4, to reach the final concentrations of 20,10 , and $10 \mathrm{mM}$, respectively. The decrease in $\mathrm{pH}$ down to $\mathrm{pH} 3.0-3.5$ upon adding glutathione into the HEPES solution completely dissolved the added ferrous sulfate and transformed nitrite into GS-NO produced during the reaction of protonated nitrite with glutathione. The efficiency of GS-NO formation was estimated by an increase in kinetics of its absorbance at $334 \mathrm{~nm}$ as well as by a slightly weaker increase at $542 \mathrm{~nm}$, with extinction coefficients of $(\varepsilon) 0.940$ and $0.17 \mathrm{M}^{-1} \mathrm{~cm}^{-1}$ [26].

After GS-NO was formed $1.5 \mathrm{~h}$ later, solution $\mathrm{pH}$ was adjusted to $7.3-7.5$ by a dropwise addition of $100 \mathrm{mM}$ $\mathrm{NaOH}$. After $15-18 \mathrm{~h}$, the rose color of the solution typical of GS-NO turned into a dark orange color typical of B-DNIC-GSH being formed.

According to Scheme 4, equal concentrations of $\mathrm{Fe}^{2+}$ and GS-NO $(10 \mathrm{mM})$ led to complete incorporation of

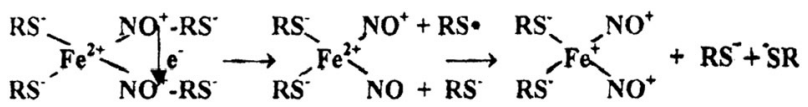

Scheme 4 The proposed mechanism of generating of M-DNIC with thiol-containing ligands during the reaction of $\mathrm{Fe}^{2+}$, thiols, and RS-NO $[3,6,13]$
GS-NO into B-DNIC (into its iron dinitrosyl group) significantly decreasing the risk of contaminating the solution with nitrite unincorporated into B-DNIC. Only about a half of $\mathrm{Fe}^{2+}$ ions $(5 \mathrm{mM}$ of $10 \mathrm{mM})$ was incorporated into BDNIC at neutral $\mathrm{pH}$. The other half precipitated in a form of iron hydroxide complexes that could be easily eliminated from the solution by filtering through a paper filter.

The concentration of the synthesized B-DNIC-GSH was determined using optical methods by measuring the intensity of absorption features of these complexes at 310 and $360 \mathrm{~nm}$ with $\varepsilon=4600$ and $3700 \mathrm{M}^{-1} \mathrm{~cm}^{-1}$ (per an iron atom) [27]. The concentration of the complexes synthesized under these conditions was $4.5-5.0 \mathrm{mM}$.

B-DNIC-MS synthesis was performed following a similar protocol but took less time than GS-NO synthesis. S-nitrosomercaptosuccinate (MS-NO) formation took 15-20 min instead of 1-1.5 h required for GS-NO synthesis, while B-DNIC-MS synthesis took no more than $1 \mathrm{~h}$ instead of 15-18 $\mathrm{h}$ required for B-DNIC-GSH synthesis. Moreover, we synthesized B-DNIC-MS using the same method but different initial concentrations of mercaptosuccinate, ferrous sulfate, and nitrite (40:20:20 mM or 80:20:20 mM instead of 20:10:10 mM).

\section{Synthesis of MNIC-MGD}

MNIC-MGD was synthesized by treatment of ferrous sulfate and MGD solutions with gaseous $\mathrm{NO}$ at $\mathrm{Fe}^{2+}$ : MGD molar ratio $1: 2$ and NO pressure $100-150 \mathrm{~mm} \mathrm{Hg}$. The synthesis was performed in a Thunberg apparatus as described in [27].

\section{Optical and EPR Assays}

Optical measurements of B-DNIC were performed on a UV-2501PC spectrophotometer (Shimadzu Europa GmbH, Germany) in a flat quartz cuvette with an optical path of $10 \mathrm{~mm}$. All measurements were performed at ambient temperature.

EPR spectra of M-DNIC and MNIC-MGD solutions were measured at $77 \mathrm{~K}$ in a quartz Dewar vessel filled with liquid nitrogen using a modified RadioPan EPR spectrometer (Poland) (microwave power, $5 \mathrm{~mW}$, modulation amplitude, $0.2 \mathrm{mT}$ ). The concentrations of paramagnetic M-DNIC and MNIC-MGD were determined by the double integration of EPR signals. A solution of M-DNIC-GSH of known concentration was used as a reference sample.

\section{Cell Culture}

MCF7 human breast cancer cell line was provided by the laboratory of the Institution of Experimental Diagnostics and Therapy of Cancer of N.N. Blokhin Cancer Research 
Center. Cells were cultured in the presence of $5 \% \mathrm{CO}_{2}$ at $37^{\circ} \mathrm{C}$ in DMEM medium (ThermoFisherScientific, USA) containing $10 \%$ fetal bovine serum, $2 \mathrm{mM}$ glutamine, and 10 units/ml penicillin-streptomycin (PanEco, Russia).

\section{The Estimation of Cell Viability by MTT Assay}

The cytotoxic activity of B-DNIC with GSH or MS was assessed by estimating the fractions of viable cells with or without treatment with B-DNIC derivatives using the standard MTT assay. A $2 \mathrm{ml}$ of cell suspension with $\sim 10^{5}$ cells in a culture medium was added to a well of a 96-well plate (each sample was measured in 4 replicates). After $24 \mathrm{~h}$ required for cell adaptation and adhesion, a solution of the mentioned above B-DNIC in sterile PBS was added at a required concentration (no more than $10 \%$ of total volume in a well). In case of combined treatment with B-DNIC and MGD, B-DNIC was added before MGD. The cells were incubated for $48 \mathrm{~h}$ in a $\mathrm{CO}_{2}$-incubator at $37^{\circ} \mathrm{C}$, and then $20 \mathrm{ul}$ of MTT reagent (3-(4,5-dimethylthiazol-2-yl)-2,5-diphenyltetrazolium bromide, AppliChem, Germany) were added to each well to obtain a working concentration of $0.5 \mathrm{mg} / \mathrm{ml}$. The cells were incubated in the presence of MTT reagent for $3 \mathrm{~h}$, then the medium was aspirated and $200 \mathrm{ul}$ of DMSO were added to each well to dissolve formazan crystals $\left(37^{\circ} \mathrm{C}\right.$, $10 \mathrm{~min}$ under agitation). The fraction of viable cells was assessed by measuring the absorbance of formazan solution at $570 \mathrm{~nm}$ using MultiscfnFC analyzer (ThermoScientific, USA) proportional to the number of viable cells.

\section{Assessing the Cell Viability using Double Staining}

This method allows estimating the population of cells that underwent either of two cell death types apoptosis and necrosis. The commercial Annexin-V FITC Apoptosis Kit (Invitrogen, США) was used. Cells were stained for $15 \mathrm{~min}$ in PBS (PanEco, Russia) containing the dye mixture in the dark at room temperature. The minimal required volume of cell suspension was $2 \mathrm{ml}$, it contained $\geq 5.10^{5}$ cells. The reaction was stopped by adding 350-400 $\mu \mathrm{l}$ of a binding buffer. Green (FITC) and red (PI) fluorescence of cells were measured using flow cytometer ACEA NovoCyte (USA) equipped with a solid-state argon laser with a wavelength of $488 \mathrm{~nm}$ and was analyzed using NovoExpress software. No less than 50,000 events were recorded, and the obtained results were presented as 2D plots of Annexin V-FITC against PI fluorescence intensities (in log scales) which were used to assess the fractions of dead and viable cells in a tested suspension (Fig. 1). Apoptotic and necrotic cells were stained by both dyes $\left(\mathrm{AV}^{+} \mathrm{PI}^{+}, \mathrm{Q} 2-2\right.$ quadrant) were considered to be dead. Early apoptotic cells, dying cells ( $\mathrm{AV}^{+} \mathrm{PI}^{-}, \mathrm{Q}^{2}-4$ quadrant), and cells permeable for $\mathrm{PI}$ in Q2-1 quadrant were considered to be dead as well.

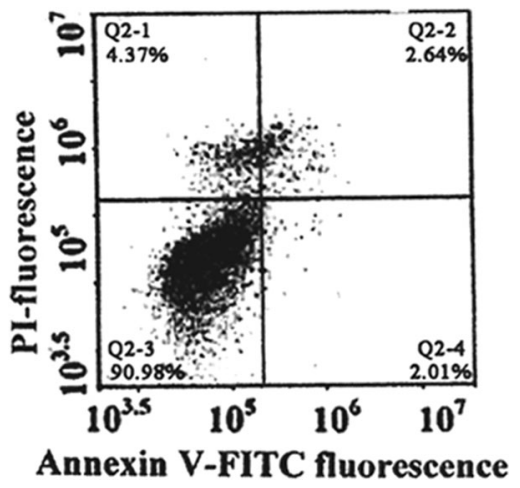

Fig. 1 The 2D plot of Annexin V-FITC versus PI fluorescence typical for intact MCF7 cells

\section{Statistical Analysis}

All results were presented as mean values of $\geq 3$ replicates \pm $\mathrm{SD}$; mean values were compared using the nonparametric Kolmogorov-Smirnov test. The difference between mean values was considered to be significant at $p \leq 0.05$.

\section{Results}

\section{The Physico-chemical Properties of B-DNIC-GSH and B-DNIC-MS}

The absorbance spectrum of B-DNIC with GSH with typical absorbance features at $310 \mathrm{~nm}$ and $360 \mathrm{~nm}$, mentioned in a Methods section, is a major characteristics of the complexes (Fig. 2, panel A, curves 1-3) and of the most of B-DNIC with thiol-containing ligands [27]. The intensity of the bands at 310 and $360 \mathrm{~nm}$ in the spectrum of synthesized B-DNIC-MS was significantly increased by additional absorbance in this region introduced by iron complexes with carbonyl groups of the mercaptosuccinate molecules that are present in commercial preparations of mercaptosuccinate. This additional absorbance altered the measured ratio of intensities and the position of the bands. These specificities of B-DNIC-MS absorption spectra disappeared upon acidification of solutions of these complexes, evidently due to the breakdown of iron complexes with mercaptosuccinate carbonyl groups. As a result, the shape and ratio of feature intensity at $310 \mathrm{~nm}$ and $360 \mathrm{~nm}$ became identical to those in the spectrum of B-DNIC-GSH (Fig. 2, panels $\mathrm{B}$ and $\mathrm{C}$, curve 2).

The main difference between B-DNIC-GSH and BDNIC-MS lied in a significantly lower stability of the MS derivative than that of the GSH derivative. After the incubation of their aqueous solutions in equal concentrations at neutral $\mathrm{pH}$ in the air, B-DNIC-GSH appeared to be stable for one day while the degradation of B-DNIC-MS began 


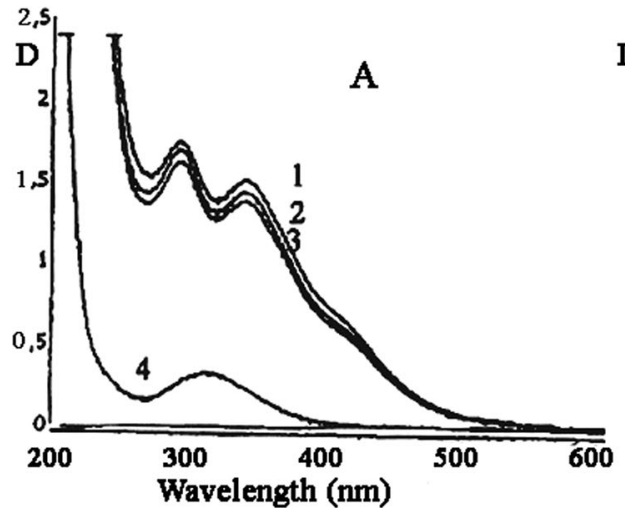

Fig. 2 The absorption spectra of $0.5 \mathrm{mM}$ solutions of B-DNIC-GSH (panel A) and B-DNIC-MS (panels $\mathbf{B}$ and $\mathbf{C}$ ) at neutral pH (pH 7.4, curve 1) and low $\mathrm{pH}(\mathrm{pH} 1-2$, curve 2-5). Solutions were incubated in the presence (panels $\mathbf{A}$ and $\mathbf{B}$ ) or absence of air (panel $\mathbf{C}$ ) at room temperature for $2 \mathrm{~min}$ (curves 2, all panels), 20, 30, or $40 \mathrm{~min}$ (curves 3,4, and 5, panel B), 50-60 min (curves 3-4, panel C). Spectrum 5 in panel $(\mathbf{C})$ was registered in a solution prepared by 10 -minute agitation of the solution 4 in the air which caused the oxidation of iron of the compound. Spectrum 6 in the same panel typical for $\mathrm{Fe}^{3+}$ ions was

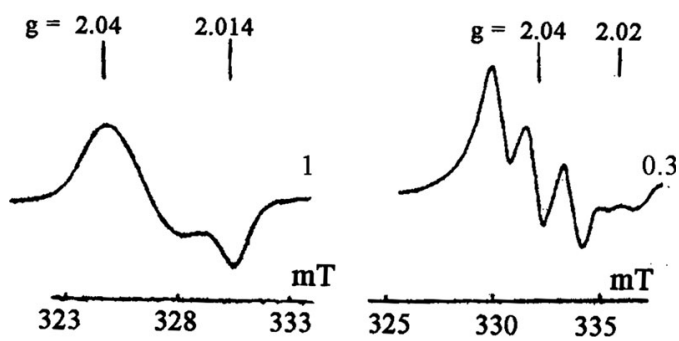

Fig. 3 EPR signals of mononuclear DNIC-MS (on the left) and MNICMGD (on the right) registered after the treatment of the B-DNIC-MS solution with excess MGD. The recording was performed at $77 \mathrm{~K}$. The EPR radio spectrometer gain (in relative units) is indicated on the right

after $1-2 \mathrm{~h}$. Under acidic conditions $(\mathrm{pH}=1-2)$, the difference in their stability was more pronounced. Under these conditions, B-DNIC-GSH was stable for more than $1 \mathrm{~h}$ (Fig. 2, panel A, curves 1-3) while the degradation of B-DNICMS began immediately after acidification both in the presence or absence of the air. The degradation rate increased as the ratio between the concentrations of MS, ferrous sulfate, and nitrite used for B-DNIC decreased. At a ratio of $2: 1: 1$, the degradation of the complexes took no more than $10-15 \mathrm{~min}$, while at a ratio of $4: 1: 1$, the degradation took $30 \mathrm{~min}$ and $1 \mathrm{~h}$ in the presence and absence of air, respectively. B-DNIC-MS absorption spectrum transformed into the spectrum typical of MS-NO with a major absorption feature at $334 \mathrm{~nm}$ and a weaker feature at $542 \mathrm{~nm}$ (Fig. 2, panels $\mathrm{B}$ and $\mathrm{C}$ ). Such a transformation occurring at low $\mathrm{pH}$ described by us before [20-22] was observed in the case of B-DNIC-GSH as well but only after $30 \mathrm{~s}$ heating at $70-80^{\circ}$ C (Fig. 2, panel A, curve 4). A similar transformation was observed in the case of B-DNIC-MS (Fig. 2, panel B, curve 6). The transformation of both B-DNIC derivatives into

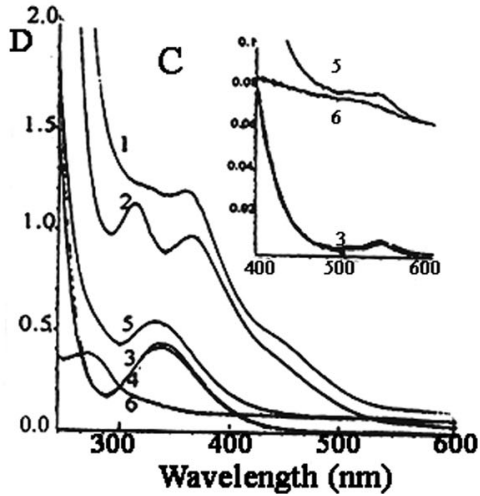

obtained by subtracting spectrum 4 from spectrum 5 . The Inset (panel C) includes spectra 3,5, and 6 registered in the range of $D$ values between 0 and 0.1 at wavelength range of $400-600 \mathrm{~nm}$. Spectra 4 and 6 in panels (A and $\mathbf{B}$ ) were registered in $0.5 \mathrm{mM}$ solutions of B-DNICGSH and B-DNIC-MS, respectively after $30 \mathrm{~s}$ heating at $80^{\circ} \mathrm{C}$. BDNIC-GSH and B-DNIC-MS were synthesized using the following ratios: $\mathrm{GSH}: \mathrm{Fe}^{2+}$ nitrite $=2: 1: 1$ and $\mathrm{MC}: \mathrm{Fe}^{2+:}$ nitrite $=4: 1: 1$, respectively

appropriate RS-NO was mediated by the breakdown of the complexes upon protonation of thiol ligands and their subsequent binding to nitrosonium cations released from the complexes as it was shown in [20-22].

Notably, the transformation of B-DNIC-GSH into GSNO was significantly delayed or completely abolished upon the elevated levels of free glutathione in a solution. This was the case during B-DNIC-GSH synthesis at a ratio of GSH $: \mathrm{Fe}^{2+}$ : nitrite $=4: 1: 1$.

In most cases, the concentration of S-nitrosothiols (RSNO) generated upon B-DNIC breakdown was equal to the concentration of the complexes in terms of 1 iron atom (0.5 mM RS-NO for $0.5 \mathrm{mM}$ B-DNIC). This is entirely consistent with the mechanism of the transformation of these complexes into corresponding RS-NO proposed in [20-22].

The proposed mechanism is consistent with the results on the treatment of B-DNIC-GSH (MS) with MGD, a water soluble derivative of dithiocarbamate. MGD can intercept iron mononitrosyl group from iron dinitrosyl fragment of the complexes forming MNIC-MGD that can be detected with EPR. Indeed, such treatment led to a loss of the weak EPR signal with $\mathrm{g}_{\mathrm{cp}}=2,03\left(\mathrm{~g}_{\perp}=2,04\right.$ and $\left.\mathrm{g}_{\|}=2,014\right)$ in the EPR spectrum of B-DNIC-GSH (MS) (Fig. 3, left panel). It was caused by a small trace of the paramagnetic mononuclear form of DNIC (M-DNIC) in the preparations. At the same time, the treatment with MGD induced a strong EPR signal of MNIC-MGD with $g_{\perp}=2,04$ and $g_{\|}=2,02$ and to the triplet hyperfine structure (HFS) at $g_{\perp}$ (Fig. 3, right panel). Judging by signal intensity, the entire iron and about a half of nitrosyl ligands (neutral NOmolecules) from B-DNIC were incorporated into MNIC-MGD. As shown in our previous work devoted to the influence of MGD on B- 

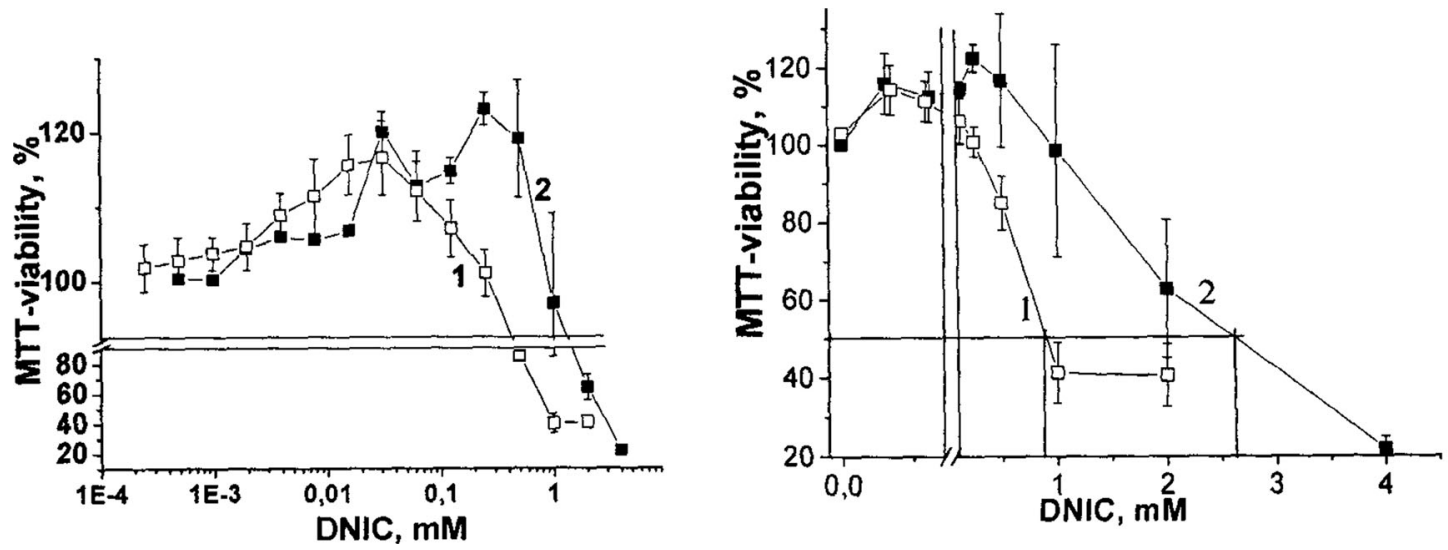

Fig. 4 DNIC dose dependence of MCF7 cell viability; left panel - log scale dose, right panel - linear scale dose; Curve $1-$ DNIC-MS (IC $50=$ 0,9MM),Curve 2- DNIC-GSH ( $\left.\mathrm{IC}_{50}=2,6 \mathrm{MM}\right)$

DNIC-GSH [28, 29], the other half of nitrosyl ligands were released from the complexes as nitrosonium cations.

\section{The Influence of B-DNIC-GSH and B-DNIC-MS on the Viability of MCF7 Cells}

Both B-DNIC preparations exerted cytotoxic activity toward MCF7 cancer cells in a dose-dependent manner, the effect of B-DNIC-MS being more pronounced (Fig. 4). The median lethal dose $\left(\mathrm{LD}_{50}\right)$ for B-DNIC-MS was $0.9 \mathrm{mM}$ and $2.6 \mathrm{mM}$ for B-DNIC-GSH. Interestingly, in both cases, low concentrations elevated the cell viability which subsequently significantly declined (Fig. 4, left panel). A similar effect was observed previously by the groups studying the influence of various DNIC with thiol-containing ligands on cultivated transformed cells as well as normal cells [30-33].

The cytotoxicity of B-DNIC-MS was almost 3 times higher than the cytotoxicity of B-DNIC-GSH accounting for the low stability of the B-DNIC-MS complexes. Their degradation resulted in the release of a sufficient amount of biologically active $\mathrm{NO}$ molecules and $\mathrm{NO}^{+}$cations from B-DNIC-MS leading to higher toxicity of B-DNIC-MS despite their lower concentration. To find out which component of B-DNIC (NO molecules or $\mathrm{NO}^{+}$) would determine the cytotoxic effects of the complexes, we used the approach from [14] and studied the influence of MGD on the cytotoxic effects of both B-DNIC. Augmentation of their cytotoxic activities by MGD would indicate a key role of $\mathrm{NO}^{+}$in the cytotoxic effects of B-DNICs.

\section{The Influence of MGD on Cytotoxic Effect of B-DNICs}

As MGD itself clearly possesses cytotoxic activity, the concentrations of DNIC with thiosulphate or B-DNIC-GSH (MS) used respectively in the experiments described in [14] and proposed in our study should be two times less and

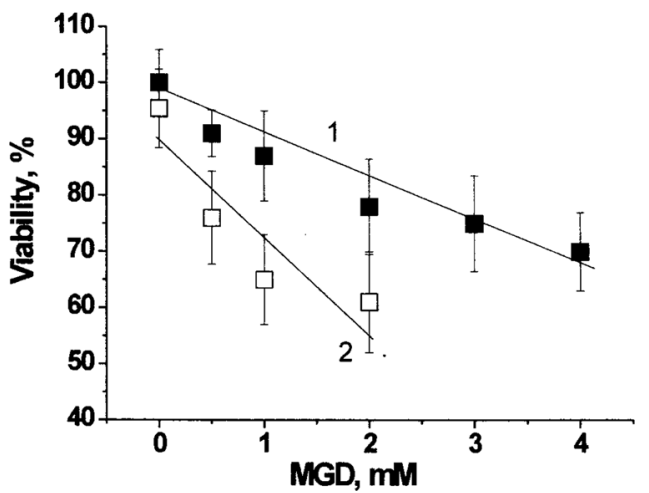

Fig. 5 MGD dose dependent decrease in viability of MCF7 cells according to MTT (line 1) and AnnexinV-FITC (line 2) assays

lower than those of MGD (see Scheme 3). Hence, MGD working concentrations we used were of $1 \mathrm{mM}$ for $0.5 \mathrm{mM}$ of B-DNIC-MS or 2 or $3 \mathrm{mM}$ for $1 \mathrm{mM}$ B-DNIC-GSH. Due to involving two MGD molecules in MNIC-MGD formation during its reaction with B-DNIC-GSH/MS the concentrations of free MGD molecules ought to be zero at a ratio of $\mathrm{B}-\mathrm{DNIC}-\mathrm{GSH} / \mathrm{MS}=1: 2$ or $1 \mathrm{mM}$ at a ration of $\mathrm{B}-\mathrm{DNIC}-\mathrm{GSH}=1: 3$. In accordance with our experimental data obtained by standard MTT assay and presented in Fig. 5 (line 1), the viabilities of MCF7-cells at zero and $1 \mathrm{mM}$ MGD concentrations were equal 100 and $90 \%$, respectively.

As followed from Fig. 6, combined addition of B-DNICGSH(MS) and MGD resulted in the augmentation of both B-DNIC cytotoxic effect. Treatment of cancer cells with B-DNIC-MS or B-DNIC-GSH with MGD at a ratio of $0.5 / 1$ (Fig. 6, left panel, column 3) or $1 / 2$ and $1 / 3$ (Fig. 6, right panel, columns 3 and 4) caused the $30 \%$ or 20 and $30 \%$ decrease in cell viability, respectively. As to MNIC-MGD cytoxicity it was not characteristic for the complexes at the concentratios of 0.5 and $1 \mathrm{mM}$ (Fig. 6). 

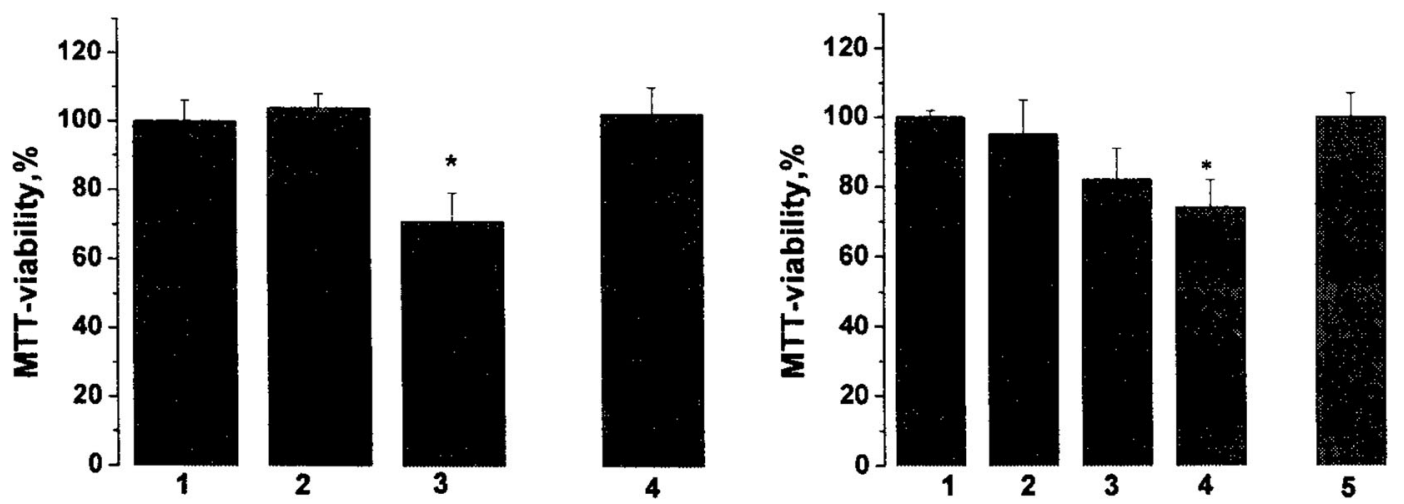

Fig. 6 Adding MGD to B-DNIC-MS or B-DNIC-GSH (left or right panels, respectively) increased the cytotoxic effect of B-DNICs estimated by MTT assay used to measure MCF7 cell viability. Millimolar ratios of B-DNIC/MGD in the cell suspension were as follows: left panel - 1- 0/0, 2- 0.5/0, 3- 0.5/1; right panel - 1- 0/0, 2- 1/0; 3- 1/2, 4- 1/3. Columns 4 and 5 (left or right panels, respectively) reflect

MTT-viability of MCF7 cells after administration of MNIC-MGD at the concentrations of $0.5 \mathrm{mM}(4)$ or $1 \mathrm{mM}$ (5).Results are presented as means of three independent experiments \pm SE. $* p<0.01$ - the differences between 1 and 3 (left panel) or between 1 and 4 (right panel) are significant; $p<0.05$ - the differences between 1 and 3 (right panel) is not significant
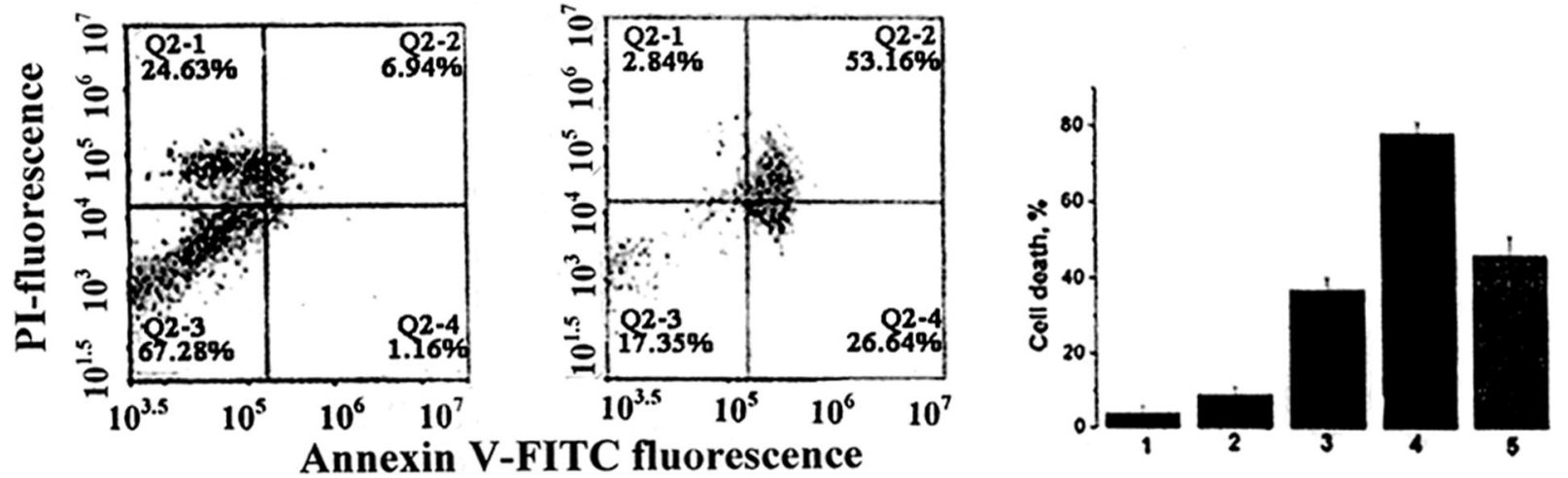

Fig. 7 MCF7 cell death in response to the treatment with B-DNIC-MS $(0,5 \mathrm{mM})$ and MGD $(1 \mathrm{mM})$ assessed with Annexin-PI staining. Left panel -. 2D plots obtained using flow cytometry. Cells were incubated with B-DNIC-MS alone (left plot) and with a mix of B-DNIC-MS and MGD (right plot). Right panel - Mean fraction (\%) of dead cells in a

The observed difference between MGD dose dependent decrease in viability of MCF7 cells according to MTT and AnnexinV-FITC (Fig. 5, lines 1 and 2) reflects the difference between sensitivity of two methods of cell death detection. MTT assay is mediated by mitochondrial cell response to stress, while AnnexinV stains phosphatidylserine exposed on the cell surface being the marker of apoptosis, and propidium iodide (PI) is excluded from the cells with intact plasma membrane and only the dead cells that are permeable for PI.

The results supporting a synergistic effect of combined treatment of MCF7 cells with B-DNICs and MGD were obtained while. assessing the cell viability using double staining. Figure 7, left panel illustrates the differences between 2D plots of AnnexinV vs PI fluorescence of the suspensions incubated with DNIC-MS with or without MDG for $48 \mathrm{~h}$. These data are summarized in the following diagram. It shows the mean percent of dead cells upon suspension. 1 - control, 2 -B-DNIC-MS, 3 - MGD (in accordance with Fig. 5, line 2), 4- B-DNIC-MS+MGD (combined action), 5 - sum of the effects in $2+3$. Results are presented as mean values from three independent experiments $\pm \mathrm{SE}$

different treatments. It indicates that the cytotoxicity B-DNIC-MS at the combined treatment Of MCF7 cells with B-DNIC-MS and MDG sharply increases.

Thus, the results presented in Figs. 6 and 7 together indicate the crucial role of nitrosonium cations in the cytotoxic effect of DNIC-MS on MCF7 cells.

\section{Discussion}

Our study confirms the findings obtained by other researchers concerning the ability of M-DNIC and B-DNIC with thiol-containing ligands to exert cytotoxic activity toward transformed cells [14, 33-35]. It should be noted here that these complexes could well exert this activity toward the normal cells $[15,30,31]$. Therefore, there is also no evidence of the specific activity of these complexes toward the transformed cells. In all these studies, the 
cytotoxic activity of DNIC was supposed to be related to their ability to act as NO molecule donors. The transformation of the latter into highly toxic peroxynitrite determines the cytotoxic activity of DNIC. Only T. Munzel group [14] suggested that the apoptosis of Jurkat human leukemia cells was induced by nitrosonium cations rather than by NO molecules. They suggested that nitrosonium cations released from M-DNIC with thiosulfate caused S-nitrosylation of the cell surface proteins.

Our results demonstrated that by an analogous mechanism, B-DNIC-GSH(MS) which have a poor membrane permeability might induce apoptosis of MCF7 cells causing S-nitrosylation of their surface proteins.

Thus, it is only natural to enquire about the possible mechanism that could mediate the breakdown of the utilized B-DNIC-GSH(MS) in MCF7 cells, the release of nitrosonium cations, and protein S-nitrosylation while preventing the action of NO molecules, the other biologically active component of B-DNIC-GSH(MS). The most likely mechanism that mediated the breakdown of these complexes was triggered by superoxide anions $\left(\mathrm{O}_{2}^{-\bullet}\right)$. As shown in [36], these free radical anions readily react with nitrosyl ligands from DNIC which can undergo a transition into a neutral $\mathrm{NO}$ molecule. This occurs as a result of an electron transfer from the central atom upon a resonance structure for B-DNIC being formed $\left[\left(\mathrm{RS}^{-}\right)_{2} \mathrm{Fe}^{2+}{ }_{2}(\mathrm{NO})_{2}\right.$ $\left.\left(\mathrm{NO}^{+}\right)_{2}\right]^{4+}$. NO binds to superoxide anion causing the formation of peroxynitrite anion in the ligand environment of an iron atom. It undergoes isomerization into nitrate which is later released from the complex causing B-DNIC breakdown. Released $\mathrm{Fe}^{2+}$ ions reduce oxygen to superoxide anions causing the further breakdown of DNIC complexes until they completely disappear.

Thus, according to the above-described mechanism, NO molecules in B-DNIC complexes act as acceptors of superoxide anions. Binding to them, NO molecules are released from the ligand environment of an iron atom in a form of nitrate anions causing degradation of DNIC complexes. The cytotoxic activity of DNIC is determined by nitrosonium cation release. The affinity of thiol-containing compounds to nitrosonium cations is known to be higher than to hydroxyl anions $[37,38]$. In the presence of thiol-containing compounds, binding of these cations to thiol-containing compounds including thiol-containing proteins can modulate their functional activity and may lead to apoptosis induction.

The probability of this transformation of thiol-containing proteins can be very high, as upon interaction of cells and tissues with DNIC with the small molecule thiol-containing ligands, iron nitrosyl groups $\left(\mathrm{Fe}(\mathrm{NO})_{2}\right)$ are transferred from low molecular DNIC to protein thiols forming more stable protein-containing M-DNIC and B-DNIC [39, 40]. Nevertheless, superoxide anions can cause complex degradation via the mechanism mentioned above [36]. Protein thiol groups in protein DNIC complexes are likely to interact with the released nitrosonium cations that modulate the activity of these proteins.

The exact mechanism of apoptosis induction triggered by S-nitrosylation of thiol-containing proteins on the cell surface remains to be studied further.

It should be noted that DNIC with thiol-containing ligands can exert the antiapoptotic activity as well as the proapoptotic activity demonstrated in this work and elsewhere $[14,15,30,31,33-35]$. The antiapoptotic activity was shown for endogenous DNIC with thiol-containing ligands produced in animal cells upon elevation of nonheme iron and NO generation [9]. NO-induced apoptosis could be completely prevented by S-nitrosylation of caspase 3 mediated by endogenous DNICs.

Does this fact contradict the evidence for proapoptotic activity of these complexes found in our and other studies? We can try to address this question bearing in mind that according to our results and data of other groups [30-32], the treatment of both transformed and normal cells with DNIC with thiol-containing ligands initially caused an increase of cell viability assessed by MTT test and only then induced cell death (Fig. 4). We cannot rule out the possibility of the elevated cell viability to be potentially explained by the penetration of a small fraction of DNICs into the cells that was sufficient for the antiapoptotic effects of the complexes, for example, mediated by S-nitrosylation of caspase 3 or other proapoptotic proteins. Upon a subsequent elevation of DNIC concentration in a cell culture medium, S-nitrosylation of the surface proteins caused by these complexes became crucial for DNIC proapoptotic activity. Thus, the results obtained in this work and elsewhere $[14,15,30,31,33-$ 35] as well as the data from [9] enrich rather than contradict each other.

The most important result of this study which demonstrated the cytotoxic activity of B-DNIC-MS components nitrosonium cations is consistent with the previous works $[9,14]$. Based on this result, one of the authors (A.V.F.) suggested that DNIC with thiol-containing ligands might be potentially useful COVID-19 treatment [41].

Funding The work is funded by the Ministry of Education and Science (State tasks for research organizations Nos. 00008202014-0001b, AAAA-A17-117040610310-b, 0082-2014-0008, and AAAA-A171170403100008-5), the Russian Academic Excellence Project 5-100, and Russian Foundation for Basic Research (grant No. 18-04-00059a).

\section{Compliance with Ethical Standards}

Conflict of Interest The authors declare that they have no conflict of interest.

Publisher's note Springer Nature remains neutral with regard to jurisdictional claims in published maps and institutional affiliations. 


\section{References}

1. Vanin, A. F. (2016). Dinitrosyl iron complexes with thiolcontaining ligands as a "working form" of endogenous nitric oxide. Nitric Oxide - Biology and Chemistry, 54, 15-29.

2. Vanin, A. F. (2018). EPR characterization of dinitrosyl iron complexes with thiol-containing ligands as an approach to their identification in biological objects: an overview. Cell Biochemistry and Biophysics, 76, 3-17.

3. Vanin, A. F. (2019). "Dinitrosyl iron complexes as a "working form" of nitric oxide in living organisms". Cambridge, UK: Cambridge Scholars Publishing.

4. Vanin, A. F., Malenkova, I. V., Mordvintcev, P. I., \& Mülsch, A. (1993). Dinitrosyl iron complexes with thiol-containing ligands and their reversible conversion into nitrosothiols. Biokhimiya, 58, 1094-1103.

5. Boese, M., Mordvintcev, P. I., Vanin, A. F., Busse, R., \& Mülsch, A. (1995). S-nitrosylation of serum albumin by dinitrosyl-iron complexes. Journal of Biological Chemistry, 270, 29244-29249.

6. Vanin, A. F., Malenkova, I. V., \& Serezhenkov, V. A. (1997). Iron catalyzes both decomposition and synthesis of S-nitrosothiols: optical and electron paramagnetic studies. Nitric Oxide Biology and Chemistry, 1, 191-203.

7. Boese, M., Keese, M. A., Becker, K., Busse, R., \& Mülsch, A. (1997). Inhibition of glutathione \ reductase by dintrosyl-irondithiolate complex. Journal of Biological Chemistry, 272, 2167-2173.

8. Boldyrev, A. A., Bulygina, E. T., Kramarenko, G. G., \& Vanin, A. F. (1997). Effect of nitroso compounds on Na/K-ATP-ase. Biochimica et Biophysica Acta (BBA) - Bioenergetics, 1321, 243-251.

9. Kim, Y. M., Chung, H. T., Simmons, R. L., \& Billiar, T. R. (2000). Cellular non-heme iron content is a determinant of nitric oxide-mediated apoptosis, necrosis, and caspase inhibition. Journal of Biological Chemistry, 275, 10954-10961.

10. Badorff, C., Fichtscherer, B., Mülsch, A., Zeicher, A. M., \& Dimeller, S. (2002). Selective $\backslash$ delivery of nitric oxide to a cellular target: a pseudosubstrate-coupled dinitrosyl iron complex inhibits the enteroviral protease 2A. Nitric Oxide - Biology and Chemistry, 6, 305-312.

11. Alencar, J. L., Chalupsky, K., Sarr, M., Schini-Kerth, V., Vanin, A. F., Stoclet, J.-C., \& Muller, B. (2003). Inhibition of arterial contraction by dinitrosyl-iron complexes: critical role of nitric oxide (NO) in determining rate of nitric oxide (NO) release and formation of releasable NO stores by S-nitrosylation. Biochemical Pharmacology, 66, 2365-2374.

12. Stojanovic., Stanic, D., Nicolic, M., Spasic, M., \& Nicetic, V. (2004). Iron catalyzes conversion of NO into nitrosonium $\left(\mathrm{NO}^{+}\right)$ and nitroxyl $\left(\mathrm{NO}^{-}\right)$species. Nitric Oxide - Biology and Chemistry, $11,256-262$

13. Vanin, A. F., Papina, A. A., Serezhenkov, V. A., \& Koppenol, W. H. (2004). The mechanism of S-nitrosothiol decomposition catalyzed by iron. Nitric Oxide - Biology and Chemistry, 10, 60-73.

14. Kleschyov, A. L., Strand, S., Schmitt, S., Gottfried, C. D., Skatchkov, M., Sjakste, N., Deiber, M., Umansky, V., \& Mönzel, T. (2006). Dinitrosyl-iron triggers apoptosis in Jurkat cells despite overexpression of Bcl-2. Free Radical Biology and Medicine, 40, 1340-1348.

15. Chen, Y.-J., Ku, W.-C., Feng, L.-T., Tsai, M.-L., Hsieh, C.-H., Hsu, W.-H., Liaw, W.-F., Hung, C.-H., \& Chen, Y.-J. (2008). Nitric oxide physiological responses and delivery mechanisms probed by water- soluble Roussin`s Red Ether and $\left\{\mathrm{Fe}(\mathrm{NO})_{2}\right\}^{9}$ DNIC. Journal of the American Chemical Society, 130, 10929-10938.

16. Bosworth, C. A., Toledo, J. C., Zmiewski, J. W., \& Lancaster, J. R. (2009). Dinitrosyliron complexes and the mechanism(s) of cellular protein nitrosothiol formation from nitric oxide.
Proceedings of the National Academy of Sciences of the United States of America, 106, 4671-4676.

17. Mayer, B., Kleschyov, A. L., Stessel, H., Russworm, M., Münzel, T., Koesling, D., \& Schmidt, K. (2009). Inactivation of soluble guanylate cyclase by stoichiometric S- nitrosation. Molecular Pharmacology, 75, 886-891.

18. Foster, M. V., Liu, L., Zheng, M., Hess, D. T., \& Stamler, J. S. (2009). A genetic analysis of nitrosative stress. Biochem, 48, 792-799.

19. Vanin, A. F., \& Burbaev, D. S. H. (2011). Electronic and spatial structures of water-soluble dinitrosyl iron complexes with thiolcontaining ligands underlying their activity to act as nitric oxide and nitrosonium ions. Biophysical Journal, 14, 818836

20. Vanin, A. F. (2018). Nitrosonium ions as a constituents of dinitrosyl iron complexes with glutathione responsible for their Snitrosating activity. Austin Journal of Analytical and Pharmaceutical Chemistry, 5(4), 1109-1119.

21. Vanin, A. F. (2019). What is the mechanism of nitric oxide conversion into nitrosonium ions ensuring S-nitrosating processes in living organisms. Cell Biochemistry and Biophysics, 77, 279-292.

22. Vanin, A. F.(2020). How is nitric oxide (NO) converted into nitrosonium cations $\left(\mathrm{NO}^{+}\right)$in living organisms? (Based on the results of optical and EPR analysis of dinitrosyl iron complexes with thiol-containing ligands). Applied Magnetic Resonance, 50 (9-10), 851-876. https://doi.org/10.1007/s00723-020-01270-6.

23. Keszler, A., Diers, A., Ding, Z., \& Hogg, N. (2017). Thiolatebased dinitrosyl iron complexes: Decomposition and detection and differentiation from S-nitrosothiols. Nitric Oxide - Biology and Chemistry, 65, 1-9.

24. Shinobu, L. A., Johnes, S. G., \& Johnes, M. M. (1984). Sodium V-methyl-D-glucamine dithiocarbamate and cadmium intoxication. Acta Pharmacologica et Toxicologica, 54, 189-194.

25. Borodulin, R. R., Kubrina, L. N., Shvydkiy, V. O., Lakomkin, V. L., \& Vanin, A. F. (2013). A simple protocol for the synthesis of dinitrosyl iron complexes with glutathione: EPR, optical,chromatographic and biological characterization of reaction products. Nitric Oxide - Biology and Chemistry, 35, 110-115.

26. Williams, D. L. H. (2004). Nitrosation reactions and the chemistry of nitric oxide. Amsterdam: Elsevier.

27. Vanin, A. F., Poltorakov, A. P., Mikoyan, V. D., Kubrina, L. N., \& Burbaev, D. S. (2011). Polynuclear water-soluble dinitrosyl iron complexes with cysteine or glutathione ligands: Electron paramagnetic resonance and optical studies. Nitric Oxide - Biology and Chemistry, 23, 136-149.

28. Vanin, A. F., Kleschyov, A. L. (1998) In Nitric Oxide in Allograft Rejection and Antitumour Defence, S. J. Lukievicz, J. L. Zweier, eds., Kluwer Academic Publishers, Norwell, MA, pp. 49-82.

29. Borodulin, R. R., Kubrina, L. N., Mikoyan, V. D., Poltorakov, A. P., Shvydkoii, V. O., Serezhenkov, V. A., Yakhontova, E. P., \& Vanin, A. F. (2013). Dinitrosyl iron complexes with glutathione as NO and $\mathrm{NO}^{+}$donors. Nitric Oxide - Biology and Chemistry, 29, 4-16.

30. Pulukkody, R., Chupik, R. B., Montalvo, S. K., Khan, S., Bhuvanesh, N., Lim, S.-M., \& Darensbourg, M. Y. (2017). Toward biocompatible dinitrosyl iron complexes: sugar- appended thiolates. Chemical Communications, 53, 1180-1183.

31. Pestol, D. C., Chupik, R. B., Khan, S., Elsabahy, M., Wooley, K. L., Darensbourg, M. Y., \& Lim, S.-M. (2019). Towards the optimization of dinitrosyl iron complexes as NO delivery agents to smooth muscle cells. Journal of the American Chemical Society, $16,3178-3187$.

32. Gizatullin, A. P., Akentieva, N. P., Sanina, N. A., Shmatko, N. Y. U., Goryachev, N. C., Shkondina, N. I., Prichodenko, T. P., Zhelev, N., \& Aldoshin, S. M. (2018). Effect of dinitrosyl iron complexes (NO donors) on the metabolic processes in human fibroblasts. Doklady Biochemistry and Biophysics, 483, 337-340. 
33. Wu, S.-C., Lu, C.-Y., Chen, Y.-L., Lo, F.-C., Wang, T.-Y., Chen, Y.-J., Yuan, S.-S., Liaw, W.-F., \& Wang, Y.-M. (2016). Watersoluble dinitrosyl iron complexes (DNIC): a nitric oxide vehicle triggering cancer cell death via apoptosis. Inorganic Chemistry, $55,9383-9392$.

34. Akentieva, N. P., Sanina, N. A., Prichodchenko, T. R., Gizatullin, A. R., Shkondina, N. I., Shushanov, S. S., Stupina, T. S., \& Aldoshin, S. M. (2019). Anticancer activity of dinitrosyl iron complex (NO donor) on the multiple myeloma cells. Doklady Biochemistry and Biophysics (Rus), 486, 238-242.

35. Sung, Y.-C., Jin, P.-R., Chu, L.-A., Hsu, F.-F., Wang, M.-R., Chang, C.-C., Chiou, S.-J., Qiu, J.-T., Gao, D.-Y., Lin, C.-C., Chen, Y.-S., Hsu, Y.-C., Wang, J., Wang, F.-N., Yu, P.-L., Chiang, A.-S., Wu, Y.-T., Ko, J.-S., Lai, P.-K., Lu, T.-T., Chen, Y. (2020) Delivery of nitric oxide with a nanocarier promotes tumour vessel normalization and potentiates anti-cancer therapies, Nature Nanotechnology https://doi.org/10.1038/s41565-019-0570-3

36. Shumaev, K. B., Gubkin, A. A., Serezhenkov, V. A., Lobysheva, I. I., Kosmachevskaya, O. V., Ruuge, E. K., \& Vanin, A. F. (2008). Interaction of reactive oxygen and nitrogen species with albumin and methemoglobin-bound dinitrosyl iron complexes. Nitric Oxide - Biology and Chemistry, 18, 37-46.
37. Wink, D. A., Nims, R. W., Darbyshir, J. F., Christodoulou, D., Hanbauer, I., Cox, G. W., Laval, F., Cook, J. A., Krishna, M., DeGraff, W. G., \& Mitchel, J. B. (1994). Reaction kinetics for nitrosation of cysteine and glutathione in aerobic nitric oxide solutions at neutral $\mathrm{pH}$. Insights into the fate and physiological effects of intermediates generated in the $\mathrm{NO} / \mathrm{O}_{2}$ reactions. Chemical Research in Toxicology, 7, 519-525.

38. Kharitonov, V. G., Sandquist, A. R., \& Sharma, V. S. (1995). Kinetics of nitrosation of thiols by nitric oxide in the presence of oxygen. Journal of Biological Chemistry, 270, 28158-28164.

39. Vanin, A. F., Serezhenkov, V. A., Mikoyan, V. D., \& Genkin, M. V. (1998). The 2.03 signal as an indicator of dinitrosyl-iron complexes with thiol-containing ligands. Nitric Oxide - Biology and Chemistry, 2, 224-234.

40. Truzzi, D. R., Alves, S. V., Netto, L. E. S., \& Augusto, O. The peroxidatic thiol of peroxiredoxin 1 is nitrosated by nitrosoglutathione but coordinates to the dinitrosyl iron complexes of glutathione. Antioxidants, 9, 276. https://doi.org/10.3390/a ntiox 9040276 .

41. Vanin, A. F. (2020). Dinitrosyl iron complexes with thiolcontaining ligands can suppress viral infections as donors of nitrosonium cation (Hypothesis). Biofizika, 65, 818-823. 